\title{
Reflections on the 2016 Nobel Memorial Prize for contract theory (Oliver Hart and Bengt Holmström)
}

\author{
NICOLAI J. FOSS \\ Bocconi University
}

PETER G. KLEIN

Baylor University

\begin{abstract}
We briefly summarize the contributions of Oliver Hart and Bengt Holmström, two key founders of modern contract theory, and describe their significance for the analysis of organizations and institutions. We then discuss the foundations of modern contract theory and review some criticisms related to modeling strategy, assumptions about knowledge and cognition, and relevance. We conclude with some suggestions for advancing contract theory in a world of uncertainty, complexity, and entrepreneurship.
\end{abstract}

\section{INTRODUCTION}

As researchers who focus on the economic theory of the firm we were delighted to see the 2016 Nobel Prize in economic sciences go to Oliver Hart and Bengt Holmström, two of the foremost economists in the areas of contracting, firm boundaries, and organizational structure. Their work has important implications not only for the theory of contracts and the theory of the firm, but also for work in strategic management, entrepreneurship, corporate governance, financial contracting, public administration, stakeholder theory, and much more.

Hart, a British economist teaching at Harvard, and Holmström, originally from Finland and now on the faculty at MIT, are leading practitioners of the formal, mathematical analysis of contracting and organizations. Hart is best known for his contributions to the 'incomplete contracting' or 'property rights' approach to the firm, while Holmström is considered the founder of modern principal-agent theory.

Authors' Note: This paper draws upon material in Foss and Foss (2000) and Foss and Klein $(2012,2013)$. 
Both have written widely in these areas; Hart has also made important contributions to principal-agent theory (Grossman and Hart 1983) and Holmström has contributed to the incomplete contracting literature (Holmström and Tirole 1989; Holmström and Roberts 1998). They have written several papers together (e.g., Hart and Holmström 1987, 2010). Both were long considered frontrunners for the prize, although earlier prizes to Williamson, Stiglitz, Spence, Akerlof, Mirrlees, Maskin, and Tirole who work on closely related issues, were often thought to have tempered their chances of receiving it.

While Hart and Holmström are known for their distinct contributions, there are important similarities between their research programs. Features of Hart's best-known contribution (Grossman and Hart 1986) are very similar to the model in one of Holmström's most famous papers (Holmström 1982). ${ }^{1}$ Methodologically, the similarities are even more striking. Both writers helped establish and popularize a distinct approach to formal modeling, 'MIT-style theory', that emerged in the late 1970s. This approach uses game theoretical, partialequilibrium models building on highly stylized, even extreme, assumptions to illustrate a particular mechanism or phenomenon. MIT theory favors parsimony, simplicity, and elegance over the more complex and more interdependent modeling style represented by, for example, Paul Samuelson's Foundations. ${ }^{2}$

MIT-style theory, at its best, simplifies complex relationships, highlights the essence of a particular approach, and provides a common language for comparing and contrasting theories (Gibbons 2005, provides an excellent example). At the same time, as we argue below, MIT theory can also lead the theorist astray. Its liberal approach to "shutting off" certain mechanisms and margins tends to result in clever, elegant, counter-intuitive results that are disconnected from reality (Foss and Foss 2000). Moreover, the "closed" modeling approach favored by MIT-style theorists suppresses the important forces of entrepreneurship, creativity, and innovation (Foss and Klein 2005). Entrepreneurship may be present in novel attempts to circumvent contractual restrictions, new ways of being morally hazardous or

\footnotetext{
${ }^{1}$ Specifically, focusing on effort instead of investment in the Grossman and Hart paper leads to the problem of aligning budget balance and Pareto optimality in the Holmstrom paper.

${ }^{2}$ As Lones Smith (2014) puts it, MIT theory "means that the paper's triumph is not in the logic or depth, but the construction of the model. A long struggle with a proof is simply a sign that the model has not been set up properly".
} 
opportunistic, new means of economizing on transaction costs, novel organizational and governance forms, etc. We argue below that contract theory ignores entrepreneurship at its peril, and we call for more integration between the study of contracts and governance structures and entrepreneurship.

\section{CONTRACT THEORY}

Contract theory is a subset of the modern economics of organization (which also includes transaction cost economics, information theory, and team theory). Contract theories are partial-equilibrium models examining small-scale interactions, focusing on (explicit and implicit) contracting relations, using non-cooperative game theory, and favoring solution concepts such as perfect Bayesian equilibrium. While emphasizing bilateral aspects of transactions, contract theory plays an important role in general-equilibrium theory. Key to the Arrow-Debreu model is the assumption that markets exist for all goods and services, including arrangements to perform or deliver in the future, contingent on particular states of the world. Put differently, a general-equilibrium model demonstrates the conditions under which organization, motivation, and governance are irrelevant. Research on moral hazard developed out of the recognition in the 1960s that all Arrow-Debreu states of nature may not be observable (or, if they are observable, not verifiable), and hence perfectly efficient incentive contracts are not feasible. Similarly, models of adverse selection and mechanism design start with the assumption that states of nature are known to agents, but not to the auctioneer, another deviation from Arrow-Debreu conditions

In this sense, modern contract theory stands squarely in the tradition of formal equilibrium modeling and is seen by its proponents as "a natural way to enrich and amend the idealized competitive model in an attempt to fit the evidence better" (Hart and Holmström 1987, 71). Analysis of contracts usually starts with an ex ante competitive equilibrium, which reduces "market forces to simple constraints on expected utilities [which] greatly facilitates equilibrium analysis" (Hart and Holmström 1987, 74) of the contracting problem. For example, reservation utilities are given, a property that greatly facilitates analysis. Given this overall characterization, a rough classification is to distinguish between complete and incomplete contract theories. The former includes principalagent and mechanism design theory, while the latter includes the property rights theories. 


\section{HOLMSTRÖM: THE PRINCIPAL-AGENT PROBLEM}

Holmström is best-known for a specific interpretation of the principalagent problem (articulated in his most-cited article, "Moral hazard and observability", Holmström [1979]). Building on earlier work by Wilson (1968) and Ross (1973), Holmström examines a situation in which one party (the 'principal') has some task to be performed, but must hire another party (the 'agent') to perform the task. Performing the task is costly to the agent, so the principal must provide some incentives to get the agent to do what the principal wants. If the principal cannot observe or understand the agent's actions directly-which is plausible, otherwise the principal could simply perform the task-then an incentive contract based on some observable, but noisy signal of output is problematic, because it exposes the agent to risks related to the noisiness of the signal. ${ }^{3}$ Hence principals face a specific tradeoff between providing incentives for agents (by using performance-based pay) and insuring agents against risks beyond their control (by using fixed salaries). Exactly how this tradeoff should be managed depends on the particulars of the situation, such as the incentive elasticity of the agent's effort, her risk preferences, the noisiness of the signals on the agent's effort, and so on.

Most of the applied literature in corporate finance and corporate governance (executive compensation, the structure of debt agreements, board composition, and so on) is based on agency theory. Holmström's (1979) "informativeness principle" suggests that principals should use all performance indicators that are available at low cost, to provide a more precise estimate of the agent's (unobservable) effort; this explains why executive compensation agreements tie compensation to multiple measures of performance such as accounting returns, stock performance, sales growth, market share, and the like. Holmström and Milgrom (1991, 1994) explore multi-task principal-agent models that show, as noted above, that pay-for-performance schemes based on objective performance metrics can induce a distortion of effort if some tasks are more easily observable than others. Under these circumstances, subjective performance measures may be valuable when used in conjunction with objective metrics (Baker et al. 1994).

\footnotetext{
${ }^{3}$ For example, incentivizing salaried managers by giving them stock options helps to align their incentives with those of shareholders, but exposes them to the risk of market fluctuations that are caused by the macroeconomic conditions, the actions of other firms, or other forces beyond their control.
} 
Contrary to common perception, agency theory does not suggest that principals always use high-powered incentives (or that incentives should necessarily be monetary or tangible). Holmström and Milgrom (1991) show that simple reward systems often outperform complex incentive contracts when employees work on multi-dimensional tasks. In this situation, incentive pay not only influences efforts and allocates risk; it also allocates the effort of agents across tasks. Some possibly essential tasks (or dimensions of a task) may be very costly to measure for the principal; as a result, the principal risks that the agent will allocate all his effort to tasks (dimensions of a task) that are easier to measure. If principals want agents to allocate effort to all tasks (dimensions of a task), they may be better off offering a fixed wage, that is, low-powered incentives. This also provides insights into organizational specialization and roles: tasks that are easily measurable may be bundled and assigned to certain kinds of jobs whereas tasks that are costly to measure are assigned to other jobs.

\section{HART: PROPERTY RIGHTS AND OWNERSHIP}

Hart's work with Sanford Grossman and with John Moore (the 'Grossman-Hart-Moore' theory of the firm) is based on a particular concept of asset ownership. Ownership is defined as residual rights of control-the right to decide how an asset will be used in situations not covered by prior agreement. ${ }^{4}$ In a world of perfect foresight (and zero contract drafting costs), individuals could write very complex and detailed contracts about how various resources will be used under particular circumstances. With contracts like these, 'ownership' is vague and indeterminate; it doesn't matter who has formal title to an asset because the asset will be used in exactly the same way. In the real world of uncertainty and imperfect foresight, however, such contracts are impossible, because we cannot anticipate every potential future event and agree in advance on what we would do. In other words, all feasible contracts are 'incomplete', meaning that they contain some omissions or gaps.

Specifically, relevant factors that may influence the contracting relationship are left out of the contract because of bounded rationality, information costs, or the limitations of natural language. Alternatively,

\footnotetext{
${ }^{4}$ Residual rights of control are seen as the defining feature of ownership, which also includes other features such as residual cash flow rights; use, exclusion, and alienability rights; and so on.
} 
partners may agree on contract terms, but these may not be enforceable by a third party, such as a court (i.e., terms are non-verifiable). Because complete contingent contracts cannot be written, parties may have to renegotiate after contracts have been signed, either because they encounter states of nature about which the contract is silent or where the contract specifies inefficient terms. Thus, in this framework there is still transactional work to be done ex post, at least in some states of the world. In the Grossman-Hart-Moore version of this idea, it is assumed that renegotiation is efficient-the outcome of renegotiation can be foreseen at the time of drafting contracts and does not involve costly bargaining. Nevertheless, the possibility of renegotiation may be enough to cause inefficient levels of investment in relationship-specific assets.

Contractual incompleteness highlights the importance of residual control rights, because these are the rights to control the use of assets in states of nature not described in the contract. Theoretical interest centers on which pattern of ownership rights leads to the most efficient outcome. This depends on the characteristics of the involved assets (e.g., whether they are complementary), whose assets are most important to the joint surplus, and who is most responsive to incentives, because ownership by one of the parties will attenuate the incentives of the other party. The bottom line is that the efficient ownership arrangements primarily turn on the trade-off between incentives for buyer and seller.

The Grossman-Hart-Moore property rights approach has given rise to substantial debate within contract theory. For example, it has been argued that property rights are not always necessary for reaching efficient outcomes, because various mechanisms that do not imply a reallocation of property rights and which are actually employed by realworld agents (say, options contracts) can handle the problems of unverifiable contract terms (Tirole 1999). Relatedly, there has been some uneasiness about the supposedly less rigorous and more ad hoc type of modeling that characterizes the incomplete contracts literature relative to the principal-agent literature (Tirole 1999).

\section{METHODOLOGICAL PERSPECTIVES ON MODERN CONTRACT THEORY}

\section{MIT-style modeling}

As noted above, the lean and elegant MIT-style of applied theory associated with Hart, Holmström, and colleagues such as Jean Tirole, Eric Maskin, Drew Fudenberg, Jean-Jacques Laffont, and Andrei Shleifer 
has costs as well as benefits. All economic theorizing uses abstraction, using various types of "isolations" under which "a limited set of items is assumed to be isolated from the involvement or influence of the rest of the world" (Mäki 2004, 320). For example, contract theorists may focus on partial equilibrium (external isolation), suppress entrepreneurship (internal isolation), assume that contract drafting costs are zero (horizontal isolation), or claim that the essence of all economic organization is to align the incentives of the involved parties (vertical isolation). As these examples suggest, one isolates by excluding (Mäki 1992), or by "suppressing margins" (Foss and Foss 2000). The analyst decides that for whatever reason, some margins are unimportant to the model and may be left out.

Isolation may be brought about by "idealizing assumptions" that explicitly mention an item, but choose extreme values for this item $(\mathrm{X}=$ 0 or $X=$ infinity or $X=1$, depending on the scale). For example, isolation in economics often takes the form of working with "on-off" models in which some variables are "switched off" by assuming that their value is zero, while others are "switched on." Alternatively, isolation may be brought about by omitting an item without mentioning it (Mäki 2004). ${ }^{5}$ Generous use of isolation typically results in a highly stylized, noncooperative game-theoretic model in which each party's objectives and preferences, the distribution of information, the sequence of moves, and so on are carefully specified. Modeling then means working "backwards" from the explanandum phenomenon to its explaining causes in terms of a "no-fat" model (i.e., models with absolute zero embellishment) (Rasmussen, 1994).

A basic problem with MIT-style theorizing is that such no-fat models provide logically sufficient, but not necessary, explanations for an observed fact. Many other explanations may be possible, though less elegantly described. Explaining by means of no-fat models is almost too easy, so that bad explanations are as easy to construct as good ones (Camerer 1994, 211). Another well-known problem with game theoretic no-fat modeling is the sensibility of equilibria to a multitude of factors, such as information partitioning, the sequence of moves, the number of players, and so on.

A somewhat different critique -more in line with the basic thrust of this paper-focuses on the specific isolations that are common in no-fat

${ }^{5}$ Long (2006), using Aristotelian language, distinguishes these as "precisive" and "nonprecisive" abstractions, respectively. 
modeling. Although its proponents may argue that no-fat modeling simply reflects fealty to Occam's razor, critics may counter that too much is excluded by means of extreme idealizing assumptions (see Furubotn and Richter 1997; Foss and Foss 2000; Foss and Klein 2012). In the following we offer examples of specific isolations in contract theory, namely those related to cognition and knowledge.

\section{Cognition and knowledge in contract theory}

Contract theory makes very strong assumptions about agents' knowledge as well as their lack thereof and this sometimes produce highly "asymmetrical" models (Foss and Hallberg 2014). To illustrate, in the basic property rights model, agents (but not the courts) are not only symmetrically and perfectly informed, they are also assumed to know the future payoffs from their relationship, even without knowing all the physical characteristics of the good being traded, let alone the kinds of unforeseen contingencies that could occur. Such model features, which border on inconsistency, are the result of on-off models, where agents are perfectly informed about some things (e.g., the distribution of utilities in a relation) and completely ignorant about other things (e.g., the sources of the utility).

To further illustrate, in the property rights approach, contractual incompleteness derives from the assumption that certain actions (say, investments) or objects may be observable by the contracting parties, but not verifiable to a third party, However, while it seems to be reasonable to assume that many things may be hard (i.e., costly) to verify to courts, why assume that some things are completely verifiable, whereas other things are completely unverifiable (Foss and Foss 2000)? The effect of this on-off approach is to suppress those ways in which contracting parties may try to make some actions or things more verifiable to courts by presenting more information to the court or presenting it in a particular way.

For this reason, Hart's approach neglects the fact that real-world courts try to reach decisions even when particular variables aren't verifiable, and that parties take this into account. What an ill-informed judge will likely decide is more important than whether a contractual clause is completely verifiable. Contract theory's emphasis on verifiability as binary (the judge is either fully informed or completely uninformed) omits the implications of actual court behavior. 
Formal incomplete contract theorists have long flirted with bounded rationality (e.g., Hart 1995, 81), but mainly used it as motivation why contracts would be incomplete. Indeed, as Hart (1990) explained bounded rationality isn't necessary, as, for example, non-verifiability (which requires asymmetric information but not bounded rationality) can also make contracts incomplete. Traditionally, economists have been skeptical of bounded rationality, partly because bounded rationality simply seems to mean "behavior that is not given to description in terms of the expected utility model" (i.e., any non-maximizing behavior), and partly because it is not obvious how to build bounded rationality into formal models in a rigorous, non-ad hoc manner. Hart's (1990) argument was therefore a license to not bother with this troublesome notion.

However, contract theorists have become more open to bounded rationality over the last decade or so (see Koszegi 2014). One reason may be that behavioral economics increasingly has become mainstream, and contract theory is certainly not immune to this. Another may stem from the Maskin and Tirole (1999) critique of the standard incomplete contracting model (e.g., Hart and Moore 1990): Given the usual assumptions of this model, it is possible to design ex post message games that ensure that the exact same allocative outcomes can be reached under incomplete as under complete contracting. Incompleteness doesn't matter for outcomes. Neither, and fatally for the theory, does ownership. To find room for ownership and restore the notion of incomplete contracting, it may therefore seem necessary to break with some of assumptions of the standard model, for example, assumptions about knowledge, cognition, and rationality.

In response to this criticism, Hart and Moore (2008) offer a contracting model based on ideas on reference points that have been central in behavioral economics since the work of Tversky and Kahneman in the early 1970 s in providing a role for long-term contracts (including employment contract). The idea is that a contract provides a reference point for the trading activity that takes place between two parties because it influences what they feel they are entitled to receive. Parties who feel shortchanged shade on performance. The tradeoff is that contractual flexibility on the one hand allows the parties to adjust to uncertainty, but on the other hand causes inefficient shading.

\section{CONCLUSIONS}

Although contract theories are game-theoretic, partial-equilibrium theories, they are fundamentally rooted, historically and logically, in the 
competitive equilibrium model (Guesnerie 1992). Work in contract economics may thus broadly be described as "de-isolating" this model in various ways, so as to bring it closer to reality (Hart and Holmström 1987), relying on MIT-style theory. However, the result of this modeling strategy is often to produce a string of loosely connected on-off contract theory models, in which margins are either completely suppressed or completely open to agents (e.g., agents are either perfectly informed or not informed at all, property rights are either perfectly enforced or not enforced at all, contracts are either fully verifiable or completely nonverifiable, etc.). There is seldom anything in-between these extreme possibilities, and it is often not clear how, and if, the many partial models add up.

It is true that contract theory in many ways have sought increased realism as multi-tasking, constraints on agents' actions, implicit contracts, private benefits, subjective performance evaluation, hierarchical layers of principals and agents, and much else has been included in the theory (see Gibbons and Roberts 2012). Still, the on-off approach remains, presumably because of its strength as an approach that is generative of new models, albeit typically highly partial models that makes sometimes very unrealistic assumptions about what agents know and what they can do in terms of contracting.

Foss and Foss (2001) argue that because of their extreme idealizing assumptions, practitioners of MIT style theorizing exclude essential aspects of the economic problems facing real word decision-makers. Economists of more heterodox stripes-such as new institutionalists, evolutionary economists and Austrian economists-may balk at the idea that everything but for a few variables is common knowledge. From these perspectives, discovery, learning, and coping with problems introduced by transaction costs constitute the essence of "the economic problem". Thus, from this perspective, a major problem with modern economic theories of the firm is that they ignore the entrepreneur (Furubotn 2002; Foss and Klein 2005): Agents are not allowed to circumvent the constraints imposed on their knowledge and actions by the modeling economist.

A related problem with MIT-style contract theory is that they often seem vulnerable to Coase's well-known criticism of "black board economics", which is founded on the notion that "[r]ealism in assumptions forces us to analyze the world that exists, not some imaginary world that does not" (Coase 1981, 18). We take Coase's 
criticism to mean that modeling should not suppress those aspects of reality that in a given explanatory context are essential. While this may sound obvious, it is arguable that contract theory often simplifies too much. To be sure, extreme and, in a sense, overly simplified models and arguments (e.g., competitive equilibrium, the Coase theorem) do have a role, namely they function an argumentum a contrario. Thus, they show the conditions that must for obtain real world institutions and arrangements like money, the firm, and the law to have no allocative consequences. However, such models may be questionable starting points for concrete theorizing. The reason is that they get closer to "realism" by throwing a few monkey wrenches into an otherwise perfect machinery, as exemplified by MIT-style on-off models. However, it borders on inconsistency to assume that, for example, agents are only boundedly rational some of the time or with respect to only a few variables or parameters, or that there is only one particular kind of transaction cost present in the economic system. ${ }^{6}$

To go back to the earlier critique-that of ignoring essential aspects of reality-, these models are also ill-equipped to handle a key player in the economy, namely the entrepreneur (Foss and Klein 2005, 2012): Agents are not allowed to circumvent the constraints imposed on their knowledge and actions by the modeling economist. In contrast, Foss and Klein (2005, 2012), building on Knight's (1912) notion of entrepreneurship as judgmental decision-making under uncertainty, link asset ownership to the nature and boundaries of the firm. In this approach, resource uses are not data, but are created as entrepreneurs envision new ways of using assets to produce goods. The entrepreneur's decision problem is aggravated by the fact that capital assets are heterogeneous, and it is not immediately obvious how they should be combined. Asset ownership facilitates experimenting entrepreneurship: acquiring a bundle of property rights is a low-cost means of carrying out commercial experimentation. Contracts are thus mechanisms by which entrepreneurs exercise judgment over productive resources as they put these resources into use.

\footnotetext{
${ }^{6}$ Furubotn and Richter $(1997,447)$ completely reject the procedure of selectively introducing a few imperfections into otherwise 'perfect' models, and argue that if one admits a role for bounded rationality and transaction costs "[t]ransaction costs must appear everywhere in the system because of the nature of the individuals making decisions [...]. Thus, once we reject the notion of the omniscient decision maker who is 'completely rational,' the economic model undergoes a basic transformation".
} 
An entrepreneurial theory of contracting, which focuses on realistic situations of limited knowledge and uncertainty, and focuses on ownership arrangements and actions designed to facilitate exchange, may be a more fruitful path forward than a continued emphasis on modeling elegance and parsimony. While the approach of Hart and Holmström has generated substantial insight into the ways economic actors organize their activities, much more is needed to incorporate these insights into a more general, dynamic understanding of the entrepreneurial market system.

\section{REFERENCES}

Baker, George, Gibbons, Robert, and Murphy, Kevin. 1994. Subjective performance measures in optimal incentive contracts. Quarterly Journal of Economics, 109 (4): 1125-1156.

Camerer, Colin. 1994. Does strategy research need game theory? In Fundamental issues in strategy: a research agenda, eds. David J. Teece, Richard Rumelt, and Dan Schendel. Boston: Harvard Business School Press.

Debreu, Gerard. 1959. Theory of value. New York: Wiley.

Foss, Kirsten, and Nicolai J Foss. 2000. Theoretical isolation in contract economics. Journal of Economic Methodology, 7 (3): 313-339.

Foss, Nicolai J., and Niklas Hallberg. 2014. How symmetrical assumptions facilitate theoretical advance in strategic management: the case of the resource-based view. Strategic Management Journal, 35 (6): 903-913.

Foss, Nicolai J., and Peter G. Klein. 2005. Entrepreneurship and the theory of the firm: any gains from trade? In Handbook of entrepreneurship: disciplinary perspectives, eds. Rajshree Agarwal, Sharon A. Alvarez, and Olav Sorenson. Berlin: Springer, 5580.

Foss, Nicolai J., and Peter G. Klein. 2012. Organizing entrepreneurial judgment. Cambridge: Cambridge University Press.

Furubotn, Erik, and Rudolf Richter. 1997. Institutions and economic theory. Ann Arbor: Michigan University Press.

Gibbons, Robert J., 2005. Four formal(-izable) theories of the firm. Journal of Economic Behavior and Organization, 58 (2): 200-245.

Gibbons, Robert J., and Roberts, John (eds.) 2012. Handbook of organizational economics. Princeton: Princeton University Pres.

Grossman, Sanford, and Oliver Hart. 1986. The costs and benefits of ownership: a theory of lateral and vertical integration. Journal of Political Economy, 94 (4): 691719.

Guesnerie, Roger. 1992. The Arrow-Debreu paradigm faced with modern theories of contracting. In Contract economics, eds. Lars Werin and Hans Wijkander. Oxford: Blackwell.

Hart, Oliver. 1990. Is bounded rationality an important part of the theory of institutions? Journal of Institutional and Theoretical Economics, 146 (4): 696-704.

Hart, Oliver. 1995. Firms, contracts and financial structure. Oxford: Clarendon Press. 
Hart, Oliver, and Bengt Holmström. 1987. The theory of contracts. In Advances in economic theory fifth world congress, ed. Truman F. Bewley. Cambridge: Cambridge University Press, 71-156.

Hart, Oliver, and Bengt Holmström. 2002. A theory of firm scope. Quarterly Journal of Economics, 125 (2): 483-513.

Hart, Oliver, and John Moore. 1990. Property rights and the nature of the firm. Journal of Political Economy, 98 (6): 1119-1158.

Hart, Oliver, and John Moore. 2008. Contracts as reference points. Quarterly Journal of Economics, 123 (1): 1-48.

Holmström, Bengt, and Paul Milgrom. 1991. Multi-task principal-agent analyses: incentive contracts, asset ownership, and job design. Journal of Law, Economics, and Organization, 7: 24-52.

Holmström, Bengt, and Paul Milgrom. 1994. The firm as an incentive system. American Economic Review, 84 (4): 972-991.

Knight, Frank H. 1921. Risk, uncertainty, and profit. New York: Augustus M. Kelley.

Koszegi, Botond. 2014. Behavioral contract theory. Journal of Economic Literature, 52 (4): 1075-1118.

Kreps, David M. 1996. Markets and hierarchies and (mathematical) economic theory. Industrial and Corporate Change, 5 (2): 561-597.

Long, Roderick. T. 2006. Realism and abstraction in economics: Aristotle and Mises versus Friedman. Quarterly Journal of Austrian Economics, 9 (3): 3-23.

Mäki, Uskali. 1992. On the method of isolation in economics. In Idealization IV: Intelligibility in science, ed. Craig Dilworth. Amsterdam: Rodopi, 317-352.

Mäki, Uskali. 1994. Isolation, idealization and truth in economics. In Idealization VI: idealization in economics, eds. Bert Hamminga and Neil B. de Marchi. Amsterdam: Rodopi, 147-168.

Mäki, Uskali. 2004. Theoretical isolation and explanatory progress: transaction cost economics and the dynamics of dispute. Cambridge Journal of Economics, 28 (3): 319-346.

Maskin, Eric, and Jean Tirole. 1999. Unforeseen contingencies and incomplete contracts. Review of Economic Studies 66 (1): 83-114.

Rasmussen, Eric. 1994. Games and information. Oxford: Basil Blackwell.

Smith, Lones. 2014. Jean Tirole and 'MIT theory'. Noise from Amerika. November 3, 2016. http://noisefromamerika.org/node/12385 (accessed 25 November 2016).

Tirole, Jean. 1999. Incomplete contracts: where do we stand? Econometrica, 67 (4): 641681.

Williamson, Oliver E. 1985. The economic institutions of capitalism. New York: Free Press.

Nicolai J. Foss is professor of organization theory at Bocconi University, Milano. His research focuses on organization design issues in strategic management and entrepreneurship theory. Foss is a member of Academia Europaea.

Contact e-mail: <nicolai.foss@unibocconi.it> 
Peter G. Klein is professor of entrepreneurship at Baylor University's Hankamer School of Business, adjunct professor of strategy and management at the Norwegian School of Economics, and Carl Menger Research Fellow at the Mises Institute. His research focuses on the links between entrepreneurship, strategy, and organization, with application to innovation, diversification, vertical coordination, health care, and public policy.

Contact e-mail: <peter_klein@baylor.edu> 